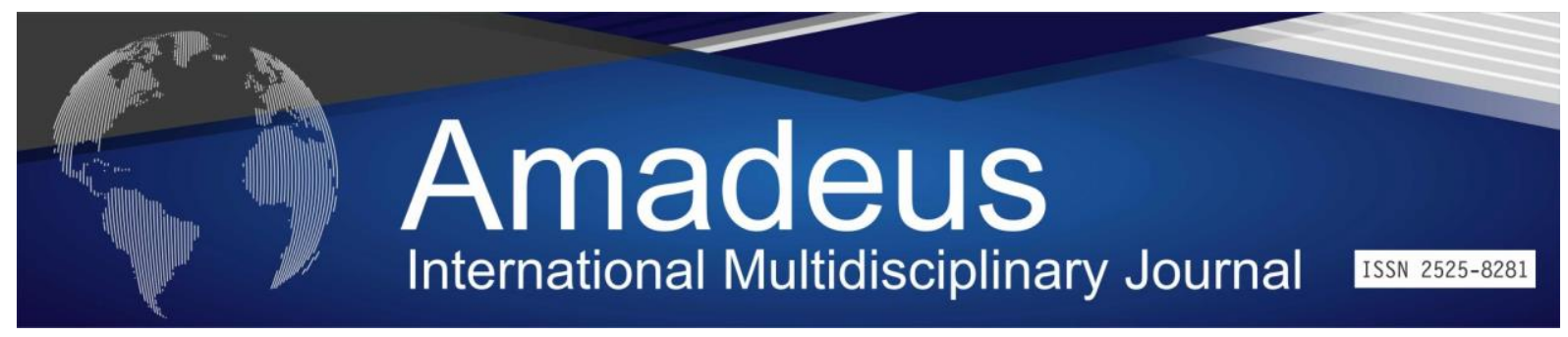

DOI: 10.14295/aimj.v5i10.160

\title{
Proeminence of Theorization of Professional Development of the Mathematics Teacher in the Early Years
}

Marcelo Máximo

Purificaçãol

Nélia Maria Pontes Amado2 Marcos Gomes Camilo3 Vanessa Alves Pereira 4 Arielly Silva Resende5
Abstract: This text arises from the discussions established in the teacher training project for the pedagogical use of technologies in the practice of Mathematics in the early years, developed within the scope of the Pedagogy course at the Centro Universitário de Mineiros - UNIFIMES, the research group NEPEM and the Graduate Program in Teaching (Doctorate) at the University of Vale do Taquari - UNIVATES. This is a qualitative review of the literature, based on the discussions of the authors used as references in the training course.

Keywords: Professional development. Mathematics teaching. Early Years.

\section{Proeminência da Teorização do Desenvolvimento Profissional do Professor de Matemática dos Anos Iniciais}

Resumo: Este texto surge das discussões estabelecidas no projeto de formação de professores para o uso pedagógico de tecnologias na prática da Matemática nos anos iniciais, desenvolvido no âmbito do curso de Pedagogia do Centro Universitário de Mineiros - UNIFIMES, do grupo de pesquisa NEPEM e do Programa de Pós--Graduação em Ensino (Doutorado) da Universidade do Vale do Taquari - UNIVATES. Esta é uma revisão qualitativa da literatura, com base nas discussões dos autores utilizados como referências no curso de formação.

Palavras-chave: Desenvolvimento profissional. Ensino da Matemática. Anos Iniciais.

\footnotetext{
${ }^{1}$ Pós-Doutor em Educação pela Universidade de Coimbra - Portugal. Doutor em Ciências da Religião pela PUCGoiás, Doutorando em Ensino pela UNIVATES. Professor Titular na Fundação Integrada Municipal de Ensino Superior de Mineiros - FIMES. E-mail: maximo@ unifimes.edu.br

${ }^{2}$ Doutoramento em Matemática, especialidade de Didática da Matemática pela Universidade do Algarve. Professora Auxiliar da Universidade do Algarve/ Portugal. E-mail: namado@ualg.br

${ }^{3}$ Mestrando em Educação pela Faculdade de Inhumas - FACMAIS. Professor da Secretaria Municipal de Educação de Goiânia - Goiás. E-mail. marcosgomescamilo@gmail.com

${ }^{4}$ Mestranda em Educação pela Universidade Estadual de Mato Grosso do Sul (UEMS). Professora substituta no centro Universitário de Mineiros - UNIFIMES e na SEDUC/GO. E-mail: vanessa.apereira@seduc.go.gov.br ${ }^{5}$ Acadêmica do Curso de Pedagogia do Centro Unicersitário de Mineiros (UNIFIMES). E-mail: arielly.jullya@gmail.com
} 


\section{Introdução}

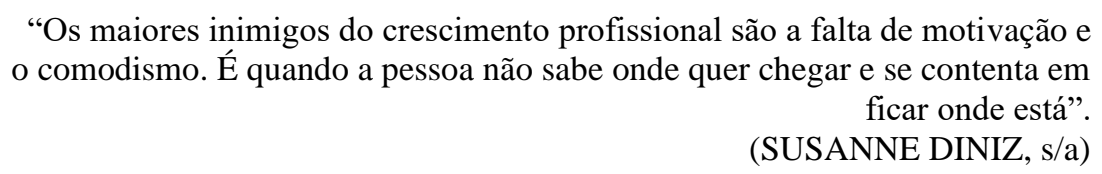

A matemática é uma das disciplinas críticas com baixos níveis de aprendizagem. Portanto, discussões que enfoquem a aquisição de conhecimentos matemáticos são importantes para o aluno, mas principalmente para o professor. O conhecimento matemático é uma referência importante para o aluno compreender o seu contexto e a sua aplicabilidade. Estudar o desenvolvimento profissional de professores e os fatores que o influenciam tem grande impotência para a formação docente. Compreender como os professores podem assumir o seu profissionalismo de forma mais plena, como podem aprofundar e tomar consciência dos seus saberes e práticas pedagógicas é um prérequisito importante para a criação de estruturas de trabalho adequadas nas escolas e para a criação de dispositivos de ensino, mais refinados e mais abrangentes. (SARAIVA; PONTE, 2003).

No contexto atual, há uma discussão geral sobre os saberes profissionais dos professores. Muito se fala sobre o perfil do professor e as demandas educacionais do século XXI. Partindo desta perspectiva, teóricos como Nóvoa (2014); Perrenoud (2000); Moran (2013); Cavalcante (2012); Shulman (1986); Mishra e Koelher (2006) se preocupam e discutem a posição do professor sobre a teoria e a prática. Verificamos também, num diálogo neste sentido, que Oliveira e Formosinho (2009, p. 225) estão atentos às considerações dos autores que "consideram a formação continuada um subsistema, componente do desenvolvimento profissional” essa nova posição/ organização dos termos se justifica, segundo os autores, na falta de resultados satisfatórios da formação contínua.

Podemos perceber pelas interposições teóricas que a formação de professores, seja inicial ou continuada, continua sendo um grande dilema. Nessa linha, como contribuição, Nóvoa (2014) enfatiza que o professor contemporâneo deve desenvolver uma postura reflexiva como prática, propiciar a troca de experiências em sala de aula e, com isso, compreender a visão de mundo do aluno, os problemas que o cercam e, sobretudo, nos 
conteúdos e no seu desempenho significativo nestes contextos. E, categoricamente, afirma que "é impossível imaginar uma mudança social que não implique na formação de professores" (NÓVOA, 1999, p. 18, grifos nossos).

Philippe Perrenoud (2000), em suas 10 competências, preconiza uma reflexão sobre a prática pedagógica que o professor deve ter para ensinar. Essa discussão é ouvida em diferentes espaços e contextos de formação em todo o mundo. Nesse sentido, o desenvolvimento profissional desempenha um papel importante nas pesquisas realizadas na educação contemporânea, uma vez que está diretamente relacionado ao conceito de competência. Nesse universo, surgem a todo o momento as linguagens dirigidas ao professor, sua formação e sua prática, tais como: “epistemologia da prática, professor reflexivo, prática reflexiva, professor-pesquisador, saberes docentes, processo de construção do conhecimento" e os termos, conhecimento e a competência ganham intensidade nos discursos da área, ampliando e promovendo debates sobre a educação e o contexto da formação docente (ALVES, 2007, adaptado).

É importante destacar que o professor de matemática dos anos iniciais é um Pedagogo, nesse universo, estudo como o desenvolvido por (BATANERO; GODINO; ROA, 2004), aponta que, embora tenham uma formação multidisciplinar voltada para uma ação profissional polivalente, a maioria dos pedagogos não gostam de matemática. Os professores com graduação em Matemática geralmente demonstram uma maior afinidade com os conceitos e conteúdos matemáticos, mas geralmente não possuem formação em tópicos relacionados ao ensino desses conceitos. Essa situação afeta ainda mais os professores dos anos iniciais, afirmam os autores.

Diante do exposto, acreditamos que as discussões sobre essa temática têm muito a contribuir para o processo de desenvolvimento profissional de alunos em formação no curso de Pedagogia, como estes que estiveram conosco, no Curso de Formação.

\section{Perfil e Conhecimentos Profissionais do Professor de Matemática dos Anos Iniciais}

O diálogo sobre a formação inicial e continuada de professores nos anos iniciais e suas práticas suscitou muitas preocupações. Como já mencionado, o desenvolvimento profissional de professores é um tema quente em pesquisas e nos mais diversos contextos. Portanto, para entender qual é o perfil e qual é o conhecimento profissional do professor 
de Matemática nos anos iniciais, devemos primeiro entender qual é a principal função dos professores que atuam na formação docente, e que têm a missão de ensinar os futuros professores. Para tanto, organizamos o diálogo nesta seção a partir das seguintes provocações: Quem é o professor de Matemática nos anos iniciais? Como seu conhecimento profissional é formado? Como as tecnologias são integradas na formação profissional de professores de Matemática nos anos iniciais? Como o conhecimento profissional dos professores que ensinam Matemática nos anos iniciais se torna prático?

Nessa busca por respostas, nos deparamos com estudos valiosos que levantam aspectos das contribuições legais da profissão e outros, relacionados às competências e aptidões necessárias à prática pedagógica dos professores nos anos iniciais. A nível internacional, destacamos Shulman (1986), Tardif (2006), Nóvoa (1992), Zeichener (1993) entre outros. Em solo brasileiro, o conhecimento profissional também é discutido e entrelaçado com a prática e os processos de ensino e aprendizagem, ampliando o discurso teórico de autores como: Pimenta (1999), Anastasiou (2006), Libâneo (2007); Freire (2011); Larossa (2004); Charlot (2005) entre outros.

Diante desse contexto e das necessidades decorrentes, Mishra e Koelher (2006), apostam no uso pedagógico das tecnologias, na perspectiva do modelo TPACK como possibilidade de ensino diferenciado. Acreditam que as tecnologias podem colaborar com a disciplina e com seu desenvolvimento, no pensar e desenvolver de situações e atividades que possam despertar o aluno para o protagonismo e uma nova personalização do processo de ensino, que segue a responsabilidade do professor em seu processo formativo. (PERRENOUD, 2000). "Desta forma, a formação de professores de matemática no uso das TIC adquire novas perspectivas e o papel do professor neste contexto tem sido repensado", afirmam Costa e Lins (2010, p. 467).

No que diz respeito especificamente aos professores que ensinam Matemática nos anos iniciais, o desenvolvimento profissional é extremamente necessário. Esses profissionais realizam sua formação inicial na graduação no curso de Pedagogia e, ao longo da formação, encontram um conjunto de conteúdos que devem dominar. Os pedagogos são professores versáteis, assumem todas as disciplinas oferecidas na primeira fase da Educação Básica, é natural que, em algumas delas, as competências e habilidades sejam construídas de forma superficial.

Para Moura (2004), na história de formação desses professores, em nosso país, até o momento atual, ainda é dominante a formação com terminalidade no magistério 
secundário, em que a Matemática é, geralmente, abordada do ponto de vista da didática dos conceitos aritméticos elementares, deixando a desejar um maior aprofundamento destes como conceitos fundamentais da Matemática e suas relações com outras áreas (MOURA, 2004).

\section{Mas afinal, quem é o professor de Matemática dos anos iniciais?}

O professor de Matemática dos anos iniciais, com base nos princípios legais que regem a educação brasileira, é um pedagogo, como já falamos anteriormente. E, para entender melhor o processo de formação desse profissional versátil, falaremos brevemente sobre alguns aspectos que norteiam as diretrizes de formação que consideramos importantes.

Para Purificação: “O professor de matemática das séries iniciais, precisa fomentar uma prática educacional que seja capaz de emancipar seus alunos, conduzindo-os a momentos ricos de reflexões e de ações transformadoras frente à sociedade na qual estão inseridos. Compreende-se que os Cursos e Programas de Formação de Professores têm como finalidade estabelecer esse elo entre formação inicial e o processo de ensinoaprendizagem e, por isso não pode acontecer descontextualizado" (PURIFICAÇÃO, 2019, p. 16.679)

Olhando para a dimensão e campos de atuação do professor pedagogo, percebe-se o grande desafio dos programas de formação de professores.

O processo de formação inicial de professores está atualmente baseado na resolução CNE / CP nº 02/2019, que especifica as diretrizes para a formação inicial de professores no país, pontuando que essa formação deve acontecer em curso de graduação (licenciaturas) ou complementação pedagógica (para bacharéis e tecnólogos).

A formação de profissionais de qualidade está ligada ao ensino de saberes que, por sua vez, está ligada à prática e aos múltiplos saberes desse professor. Desse ponto de vista, pode-se deduzir que, embora as licenciaturas em Pedagogia apresentem um equilíbrio entre a quantidade de carga horária práticas e teóricas, elas ainda "são insuficientes para garantir uma adequada formação docente: faz-se necessário que o professor vivencie ação pedagógica e reflita sobre suas posturas, práticas e contextos" (MOTTA, 2012, p. 52, adaptado). 
Ademais, Barbosa (2004) especifica que "na dinâmica da formação docente, é necessário discutir continuamente os objetivos, as funções do educador e como essas questões podem ser vistas como geradoras de resultados. Cada vez mais satisfatório” (p. 9). Nesse contexto, "aprender a ensinar é um processo que continuo ao longo da carreira docente e que, não obstante a qualidade do que fizermos nos nossos programas de formação de professores, na melhor das hipóteses só poderemos preparar os professores para começar a ensinar" (ZAICHER, 1993, p. 55. Assim, Shulmann (1987, p. 106) expressa que na educação (no contexto de ensino) "a base é o conjunto de compreensões, conhecimentos, habilidades e disposições que um professor necessita para atuar efetivamente em uma dada situação de ensino".

\section{Como é constituído o conhecimento profissional dos professores dos anos iniciais?}

Quando olhamos para a formação de alunos dos cursos de Pedagogia em suas práticas de estágio, principalmente quando a ênfase está no ensino de Matemática, percebemos seu caráter diagnóstico, em que o conhecimento do conteúdo da disciplina não é explícito. Ou seja, os futuros professores não conseguem convencer ou despertar nos alunos a importância dos conhecimentos que transmitem. Diante desse problema, García (1999) afirma que o conhecimento que o professor deve ter sobre o conteúdo/ disciplina deve passar pela função da estrutura da disciplina e ser estruturado de acordo com as necessidades dos alunos.

Para Nóvoa (2000), a formação profissional dos professores está ligada à trajetória ou percurso de vida e à formação do indivíduo. Teóricos que compartilham com ele: Gonçalves (1998), Manfredo (2013); Serrazina (2002); Shulman (2004, 2005); Mizukami (2004), especificam que "o ensino do conhecimento" ou "o ensino do conhecimento" são balizas para o ensino e discussão do desempenho e desenvolvimento profissional dos professores em suas pesquisas.

Os perfis dos professores universitários responsáveis pela formação de novos professores da educação básica, atualmente, distinguem-se pelo âmbito da formação e da prática, que podem nortear os caminhos a seguir, rumo à construção de um perfil docente capaz de integrar o ensino, pesquisa e extensão. Nesse universo, Gonçalves (1998), discutindo a formação de professores-formadores, destaca que "muitos dos problemas 
vinculados ao ensino superior podem encontrar resposta na formação de seus professores" (MANFREDO, 2013).

Serrazina (2002) também chama a atenção para as experiências dos professores, pois muitos de nossos alunos dos cursos de graduação aprendem com a observação de seus mestres. Serrazina (2002) também destaca que o professor-formador promove entre os futuros professores um modelo didático a ser seguido. Com tudo isso, é fato que nessa trajetória há a formação do futuro professor, ancorada em uma trajetória marcada por experiências e ações que podem permitir ao futuro profissional, conhecimentos e saberes diversificados.

Shulman (2004, 2005) e Mizukami (2004) defendem a aplicabilidade do ensino, fazendo, com base em testes que envolvem, conhecimentos e aprendizagem para ensinar. Diante da perspectiva anunciada pelos teóricos, entende-se que o saber do professor está atrelado aos significados e aos métodos de constituição do saber do professor em torno de uma aprendizagem diversificada em que operam com a prática, a reflexão e a ação educativa a própria construção da ação educativa. Diante desse novo contexto marcado pela diversidade, complexidade e abrangência de novas configurações, entendemos que a formação inicial de professores deve ter o ensino-aprendizagem como um elemento central.

Portanto, conhecimentos específicos devem estar associados ao processo de desenvolvimento. Para contextos como o nosso, Shulman (1986) propõe o TPACK Modelo de conhecimento tecnológico e pedagógico de conteúdos, como modelo de conhecimento pedagógico profissional e, neste estudo específico, direciona ao professor de Matemática. O modelo TPACK tem potencializado docentes e acadêmicos de cursos de formação de professores a um fazer diferenciado. Diante o exposto, é necessário empreender esforços no aprimoramento de técnicas, métodos e modelos, que visem ao desenvolvimento profissional de quem na prática faz o processo de ensino acontecer.

\section{Como as tecnologias se integram na formação profissional do professor de Matemática dos anos iniciais?}

A Resolução 02/2015, que não chegou ser plenamente integralizada, trazia como orientação para a formação de professores aspectos sobre o conhecimento tecnólogico, entre esses, podemos citar o estabelecido no artigo $2^{\circ}, \S 2^{\circ}$, que preceitua: 
Art. $2^{\circ}$ As Diretrizes Curriculares Nacionais para a Educação Inicial e Continuada do Ensino Superior dos Profissionais da Educação Básica aplicam-se à formação de professores para o exercício da docência na educação infantil, fundamental, médio e nas respectivas modalidades educacionais. (Educação de Jovens e Adultos, Educação Especial, Educação Profissional e Tecnológica, ...). [...] § $2^{\circ}$ No exercício da docência, a ação do profissional docente da educação básica está impregnada de dimensões técnicas, políticas, éticas e estéticas por meio de uma formação sólida, que envolve o domínio e gestão de conteúdos e metodologias diversas linguagens, tecnologias e inovações, contribuindo para ampliar a visão e a atuação desse profissional (BRASIL, 2015, p. 03, grifo nosso).

A resolução em questão destacou a necessidade de agregar, ainda nos cursos de formação inicial de professores, elementos essenciais que permitissem aos graduandos do Curso de Pedagogia e/ou de outras licenciaturas, desenvolver competências para a gestão e pleno domínio das ações e práticas pedagógicas, bem como de como utilizar tecnologias e inovações no ensino da Educação Básica.

Nessa perspectiva, apontamos também, como ponto relevante da Resolução no 2 , em relação à inserção de tecnologias no processo de formação inicial de professores, o fato de que se especifica que a formação dos futuros professores deve garantir um caráter emancipatório e processo permanente de educação, a partir do reconhecimento da especificidade do trabalho docente. E, para que este trabalho seja significativo e conduza a uma ação pedagógica efetiva, o Art. 5, VI, sugere: “o uso competente das Tecnologias da Informação e Comunicação (TIC) para a melhoria da prática pedagógica e a ampliação da formação cultural de professores e alunos" (BRASIL, 2015, p. 06).

Ainda assim, atentando-se às considerações da Resolução n. ${ }^{\circ}$ 2/2015, nos deparamos com mais algumas inovações também tidas como marcos positivos para reforçar a importância da utilização das TIC no processo de formação inicial de professores. Segundo eles, [...] "os egressos da formação inicial e continuada devem possuir um repertório de informações e habilidades compostos por uma pluralidade de saberes teóricos e práticos" (BRASIL, 2015, art. 7, p. 7).

Portanto, quando focamos a discussão sobre o ensino do conhecimento na formação inicial de professores para o uso das TIC, fica claro que a relação entre as TIC e a educação e, consequentemente, com o ensino (no nosso caso de pesquisa, o ensino superior - formação de professores), está diretamente ligada às necessidades determinadas pelo novo cenário social. 


\section{Como é posto em prática o conhecimento profissional dos professores que ensinam matemática nos anos iniciais?}

Para que a formação do professor de matemática nos anos iniciais seja efetiva, a busca pelo conhecimento deve ser contínua. Independentemente de onde ocorra e das circunstâncias de como o processo de formação inicial foi desenvolvido, deve preparar minimamente o professor para iniciar seu trabalho.

No entanto, praticar matemática nos anos iniciais não é fácil. Muitos professores enfrentam grandes desafios, alguns, de ordem didática, outros epistemológicos, pois a grande maioria desses professores foi, e ainda são formados dentro de uma dinâmica tradicional e linear, o que nem sempre gera uma aprendizagem satisfatória. Estás posto, o grande desafio didático, porque o professor ainda apresenta uma metodologia instrucional, menos construtivista e epistemológica, o que reforça a necessidade de se desenvolver conhecimentos elementares e necessários ao ensino básico (SANTOS, 2015).

Para D'Ambrósio (1993), o professor precisa trabalhar a matemática com um olhar investigativo. Ou seja: (...) o ensino avança como resultado da investigação e resolução de problemas. Além disso, é importante que o professor compreenda que a matemática estudada deve, de alguma forma, ser útil para os alunos, ajudando-os a compreender, explicar ou organizar a sua realidade (p. 35, adaptado).

É preciso desfazer o estereótipo social de que quem não gosta de matemática deve fazer pedagogia. "A Matemática continua a ser vista como uma Ciência nobre, perfeita, e que nem todos são capazes de possuir esse conhecimento e, portanto, terão que escolher carreiras nas quais esse conhecimento não seja necessário" (SANTOS, 2015, p. 5). Essa visão tem contribuído muito para a desmotivação de alguns alunos do Curso de Pedagogia, que gostam de matemática e muitas vezes veem seu ensino nivelado por baixo, visto que a grande maioria dos colegas não gostam da matemática, alimentando um ciclo que, nefastamente, tem se repetido.

Diante do exposto, nos diálogos de D'Ambrósio e Santos, trazemos as concepções de Imbernón (2011), que propõe uma reflexão sobre o papel assumido pela formação docente; isso deve ir além da mera atualização científica, pedagógica e didática e transformá-la em algo crítico, reflexivo, participativo e transformador, gerador de mudanças. 
Ainda segundo Imbernón (2009),

O desconforto das práticas processuais por parte de um especialista infalível ou acadêmico são vistos como ignorantes que procuram resolver os problemas dos professores, muitas vezes sem experiência prática na docência, exigindo por parte dos formadores, diferentes metodologias (IMBERNÓN, 2009).

O que resta das concepções de Imbernón (2009-2010) e D'Ambrósio (1993) é a visão da formação continuada como perspectiva de mudança e promoção do desenvolvimento pessoal e profissional dos professores. Considerando quem trabalha com Matemática nos anos iniciais, eles precisam entender o que é matemática, sua constituição como Ciência/disciplina, os diferentes métodos e formas de trabalhá-la, e como transformá-la em algo substancial, isto é, significativo e essencial para o aluno.

\section{Considerações Finais}

Diante do exposto, Nóvoa (1999) afirma que não conseguiremos evitar a "pobreza de práticas" (p. 17) e Lacerda e Melo (2017) respondem: "se não tivermos políticas que reforcem os professores, seus saberes e seus campos de atuação, que valorizam as culturas docentes, que não transformem a docência em uma profissão dominada por estudantes universitários, especialista. Lembrando que a formação de professores não se baseia no acúmulo de cursos, conhecimentos e técnicas. A formação deve ser um processo, baseado na (auto) reflexão das práticas, e a partir daí buscar o desenvolvimento e com ele a (re) construção de um perfil profissional (NÓVOA, 1995).

$\mathrm{Na}$ perspectiva de Nóvoa, entendemos que o ensino da matemática deve ser desenvolvido com clareza. Ao desenvolver o plano de aula, o professor deve pensar em estratégias e métodos em que a matemática se articule com as experiências e práticas dos alunos. A formação (inicial ou contínua) de professores de matemática nas séries iniciais precisa perceber que os contextos sociais, vistos a partir da lupa do conhecimento matemático, podem fornecer conhecimentos e saberes capazes de ajudar os professores a melhorar sua prática pedagógica, bem como a lidar com com diferentes situações; a sala de aula deve ser um local de transposição dos conhecimentos adquiridos (MACHADO, 1994).

Em consonância com essas ideias, Curi (2004) aponta como elemento central e necessário que o professor, ao assumir a disciplina de Matemática nos anos iniciais, precisa 
desenvolver a compreensão e, neste contexto, vislumbrar a Matemática sob diversos aspectos, entre os quais podemos citar: o domínio dos conteúdos, das abordagens didáticas a que esses conteúdos serão inseridos e da organização do currículo. Colaborando, Perrenoud (2000) destaca a necessidade de o professor associar a relação entre os conteúdos com a proximidade dos contextos dos alunos e, a partir daí, adaptá-los para que sejam compreensíveis e, com isso, analisar previamente as deficiências existentes e as habilidades que o professor de matemática precisa conhecer e desenvolver em sua epistemologia.

\section{Referências}

ALVES, W. F. A formação de professores e as teorias do saber docente: contextos, dúvidas e desafios. Educação e Pesquisa, São Paulo, v. 33, n. 2, p. 263-280, mai./ago. 2007

ANAStaSiOU, L. das G. C.; ALVES, L. P. (Orgs.). Processos de ensinagem na universidade: pressupostos para as estratégias de trabalho em sala de aula. 6 . ed. Joinville, SC: Univille, 2006.

BARBOSA, R. L. L. Trajetórias e perspectivas da formação de educadores. São Paulo: Editora UNESP, 2004.

BRASIL. Ministério da Educação. Lei de Diretrizes e Bases da Educação Nacional. Lei no 9.394 de 20 de dezembro de 1996. Diário Oficial da União de 23 de dezembro de 1996. Brasília, 1996.

BRASIL. Resolução no 2, de 20 de dezembro de 2019. Define as Diretrizes Curriculares Nacionais para a formação inicial em nível superior (cursos de licenciatura, cursos de formação pedagógica para graduados e cursos de segunda licenciatura) e para a formação continuada. $\quad 2019 . \quad$ Brasília, Disponível em: https://abmes.org.br/arquivos/legislacoes/Resolucao-CNE-CEB-002-2019-12-20.pdf. Acesso em: 24 fev. 2020.

CAVALCANTE, M. M.; SANTOS, L. W. Referenciação e marcas de conhecimento partilhado. Linguagem em (Dis)curso, Tubarão, SC, v. 12, n. 3, p. 657-681, set./dez. 2012.

CHARLOT, B. Relação com o saber, Formação de Professores e Globalização: questões para a educação hoje. 1. ed. Porto Alegre: ARTMED, 2005.

COSTA, M. L. C.; LINS, A.F. Trabalho colaborativo e utilização das tecnologias da informação e comunicação na formação do professor de Matemática. Educação Matemática Pesquisa, São Paulo, v. 12, n. 3, p. 452-470, 2010. 
CURY, H. N. Análise de erros em disciplinas matemáticas de cursos superiores In: SEMINÁRIO INTERNACIONAL DE PESQUISA EM EDUCAÇÃO MATEMÁTICA, 3., 2006, Águas de Lindóia. Anais... Recife: SBEM, 2006. 1 CD-ROM.

D’AMBROSIO, U. Etnomatemática: um programa a educação matemática. Revista da Sociedade Brasileira de Educação Matemática, [S.1.], v. 1, n. 1, p. 5- 11, 1993.

FIORENTINI, D.; NACARATO, A. M.; PINTO, A. R. Saberes da experiência docente em Matemática e Educação Continuada. Quadrante: Revista teórica e de investigação. Lisboa: APM, 1999.

FREIRE, P. Pedagogia da Autonomia: saberes necessários à prática educativa. 43. ed. São Paulo: Paz e Terra, 2011.

GARCIA, C. M. Formação de professores para uma mudança educativa. Porto: Porto Editora, 1999.

GONÇALVES, J. A. M. A carreira das professoras do ensino primário. In: NÓVOA, A. (Org.). Vidas de professores. 2. ed. Porto: Porto Editora, 2000. p. 141-170.

GRAEBIN, Rosani Elisabete; BERTELLI, Janine; MATTE, Juliana, FACHINELLI, Ana Cristina. Conhecimento Tácito: Revisitando o Conceito de Michael Polanyi. In: XVI Mostra de Iniciação Científica, Pós-graduação, pesquisa e extensão UCS, 28 e 29 de outubro de 2016. Anais... Caxias do Sul, 2016.

IMBERNÓN, F. Formação permanente do professorado: novas tendências. São Paulo: Cortez, 2009.

KOEHLER, M. J.; MISHRA, P. Introducing Technological Pedagogical Knowledge. In: AACTE (Eds.). The handbook of technological pedagogical content knowledge for educators. New York, NY: MacMillan, 2008. p. 3-30.

LARROSA, J. Linguagem e educação depois de Babel. Belo Horizonte: Autentica, 2004. LIBÂNEO, J. C. et al. Educação escolar: políticas, estrutura e organização. 5. ed. São Paulo: Cortez, 2007.

MACHADO, M. M. O brinquedo-sucata e a criança: a importância do brincar; atividades e materiais. São Paulo: Loyola 1994. 111p.

MANFREDO, E. C. G. Saberes de professores formadores e a prática de formação para a docência em matemática nos anos iniciais de escolaridade. 2013. 233 f. Tese (Doutorado em Educação em Ciências e Matemática) - PPGECM-UFPA. Universidade Federal do Pará, Belém, 2013.

MISHRA, P.; KOEHLER, M. J. Technological Pedagogical Content Knowledge: A framework for teacher knowledge. Teachers College Record, [S.1.], v. 108, n. 6, p. 10171054, 2006. 
MIZUKAMI, M. G. N. Aprendizagem da docência: algumas contribuições de L. S. Shulman. Revista Educação, v. 29, n. 2, 2004. Disponível em: https://periodicos.ufsm.br/reveducacao/article/view/3838. Acesso em: 08 dez. 2005.

MORAN, J. M. A integração das tecnologias na educação. A Educação que desejamos: novos desafios e como chegar lá. 5. ed. Campinas: Papirus, 2013, p. 89-90. Disponível em: http://periodicos.puccampinas.edu.br/seer/index.php/reveducacao/article/viewFile/121/108. Acesso em: 21 mai. 2016.

MOTTA, Carlos Eduardo Mathias. Novas Tecnologias no Ensino da Matemática. Universidade Aberta do Brasil, 2008.

MOURA, M. O. de. Pesquisa colaborativa: um foco na ação formadora: In: BARBOSA, R. L. L. (Org.). Trajetórias e perspectivas da formação de educadores. São Paulo: Editora, UNESP, 2004, Cap. 18, p. 257-284.

NACARATO, A. M. A escola como lócus de formação e de aprendizagem: possibilidades e riscos da colaboração. In: FIORENTINI, D.; NACARATO, A. M. (Org.) Cultura, formação e desenvolvimento profissional de professores que ensinam Matemática: investigando e teorizando a partir de prática. São Paulo: Musa Editora, 2005. p. 175-195.

NONAKA, I.; TAKEUCHI, H. Criação do conhecimento na empresa: como as empresas japonesas geram o conhecimento na empresa. Rio de Janeiro: Campus, 1997.

NÓVOA, A. Os professores na virada do milênio: do excesso dos discursos à pobreza das práticas. Educação e Pesquisa, [S.1.], v. 25, n. 1, 1999.

NÓVOA, A. Professores principiantes: porque é que não fazemos aquilo que dizemos que é preciso fazer? In: CONGRESSO DE PROFESSORES PRINCIPIANTES E INSERÇÃO PROFISSIONAL À DOCÊNCIA, IV., 2014, Curitiba. Materiais do Congresso. Curitiba, 2014.

NÓVOA, A. Profissão Professor. Porto: Porto Editora, 1995.

PERRENOUD, P. “Construir competências é virar as costas aos saberes?” Revista Pátio, Porto Alegre: ARTMED, ano 03, n. 11, p. 15-19, jan. 2000.

PIMENTA, S.G. Formação de professores: Identidade e saberes da docência. In:

PIMENTA, S.G. (Org.) Saberes pedagógicos e atividade docente. São Paulo: Cortez, 1999.

PURIFICAÇÃO, M.M. Desafios e perspectivas da pesquisa em educação matemática, em contexto de formação inicial de professores pedagogo. Braz. J. of Develop., Curitiba, v. 5, n. $9, \quad$ p. 16675-16688, sep. 2019. Disponível em: https://www.brazilianjournals.com/index.php/BRJD/article/viewFile/3468/3289. Acesso em: 20 dez. 2020. 
OLIVEIRA-FORMOSINHO, Júlia. Desenvolvimento profissional dos professores. In: FORMOSINHO, João (Coord.). Formação de professores: aprendizagem profissional e acção docente. Porto: Porto Editora, 2009.

SANTOS, R. P. C. A integração das TIC no ensino de Matemática do $10^{\circ}$ CEB distrito de Aveiro. 2015. 113 f. Dissertação (Mestrado) - Departamento de Educação da Universidade de Aveiro, Aveiro, 2015. Disponível em: https://ria.ua.pt/bitstream/10773/16348/1/Tese.pdf. Acesso em: 10 mai. 2019.

SARAIVA, M.; PONTE, J. P.. O trabalho colaborativo e o desenvolvimento profissional do professor de matemática. Quadrante, v. 12 (2), p. 25-52, 2003. Disponível em: http://www.periodicoseletronicos.ufma.br/index.php/cadernosdepesquisa/article/view/8077 . Acesso em: 12 junho 2006.

SERRAZINA, L. Novos professores: primeiros anos de profissão. Quadrante - Revista de Investigação em Educação Matemática, [S.1.], v. 11, n. 2, p. 55-73, 2002.

SHULMAN, L. Just in case: reflections on learning from experience. In: COLBERT, J.; TRIMBLE, K.; AND DESBERG, P. (Ed.). The case for education: contemporary approaches for using case methods. Needham Heights, Massachusetts: Allyn \& Bacon, 1996. p. 197-217.

SHULMAN, L. Just in case: reflections on learning from experience. In: COLBERT, J.; TRIMBLE, K.; AND DESBERG, P. (Ed.). The case for education: contemporary approaches for using case methods. Needham Heights, Massachusetts: Allyn \& Bacon, 1996. p. 197-217.

TARDIF, M. Saberes docentes e formação profissional. Petrópolis, RJ: Vozes, 6 ed, 2006.

ZAMBELO, E. A. O uso de jogos de empresas no ensino superior: um estudo sobre a prática docente. 2011. Dissertação (Mestrado) - Programa de Pós-Graduação em Engenharia de Produção da Universidade Estadual Paulista Júlio de Mesquita Filho, Bauru, 2011.

ZEICHNER, K. M. A formação reflexiva de professores, ideias e práticas. Lisboa: EDUCA, 1993.

\section{How to cite this article (APA format):}

Purificação, Marcelo Máximo; Amado, Nélia Maria Pontes; Camilo, Marcos Gomes; Pereira, Vanessa Alves; Resende, Arielly Silva. (2021). Proeminence of Theorization of Professional Development of the Mathematics Teacher in the Early Years. Am. In. Mult. J., Mar. to Jun. (10) 5, 37-50.

Received: 04/02/2021

Accepted: 02/06/2021 